See discussions, stats, and author profiles for this publication at: https://www.researchgate.net/publication/343255123

\title{
Acquired Capability for Suicide Among Belgian and Australian University Students: Psychometric Properties of the German Capability for Suicide Questionnaire and a test of the Inter...
}

Article in Suicide and Life-Threatening Behavior · July 2020

DOI: $10.1111 /$ stb.12721

CITATIONS

0

8 authors, including:

David Preece

Curtin University

32 PUBLICATIONS 179 CITATIONS

SEE PROFILE

Mark Boyes

Curtin University

128 PUBLICATIONS 2,205 CITATIONS

SEE PROFILE

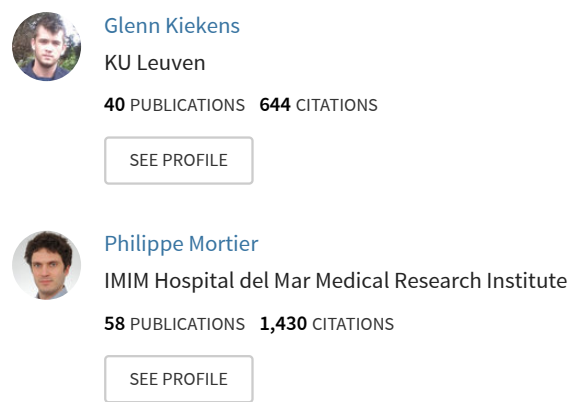

Some of the authors of this publication are also working on these related projects:

Exploring the role of habit and self-regulation in medication adherence: A qualitative analysis View project

The nature of word learning and memory in children with developmental language disorder View project 
Acquired Capability for Suicide Among Belgian and Australian University Students:

Psychometric Properties of the German Capability for Suicide Questionnaire and a test of the Interpersonal Theory of Suicide

PREECE, D.A., KIEKENS, G., BOYES, M., MORTIER, P., NOCK, M.K., KESSLER, R.C., BRUFFAERTS, R., HASKING, P.

Preece, D.A., Hasking, P., \& Boyes, M. School of Psychology and Speech Pathology, Curtin University, Perth, Australia.

Kiekens, G. Department of Neurosciences, Center for Public Health Psychiatry, KU Leuven, Leuven, Belgium. School of Psychology and Speech Pathology, Curtin University, Perth, Australia.

Bruffaerts, R. Department of Neurosciences, Center for Public Health Psychiatry, KU Leuven, Leuven, Belgium. Institute for Social Research, Population Studies Center, University of Michigan, Ann Arbor, MI, United States

Mortier, P., Health Services Research Group, IMIM (Hospital del Mar Medical Research Institute), Barcelona, Spain; CIBER Epidemiología y Salud Pública (CIBERESP), Madrid, Spain; Center for Public Health Psychiatry, KU Leuven, Leuven, Belgium.

Nock, M.K. Department of Psychology, Harvard University, Cambridge, MA, USA

Kessler, R.C. Harvard Medical School, Department of Health Care Policy, Harvard University, Boston, MA, USA.

\section{Corresponding author:}

Penelope Hasking

School of Psychology

Curtin University, Perth, Australia

E-mail: Penelope.Hasking@ curtin.edu.au

Manuscript accepted for publication in Suicide and Life-Threatening Behavior, 20 July 2020. 


\section{ACKNOWLEDGEMENTS}

The Leuven College Survey and the Curtin Wellbeing Survey were carried out in conjunction with the World Health Organization World Mental Health survey initiative and is a part of the World Mental Health International College Student Initiative. The WMH survey is supported by the National Institute of Mental Health (NIMH; R01MH070884), NIMH R56MH109566 (RPA), the John D. and Catherine T. MacArthur Foundation (MKN), the Pfizer Foundation, the US Public Health Service (R13-MH066849, R01-MH069864, and R01 DA016558), the Fogarty International Center (FIRCA R03-TW006481), the Pan American Health Organization, Eli Lilly and Company, Ortho-McNeil Pharmaceutical, GlaxoSmithKline, and Bristol-Myers Squibb. A complete list of all within-country and cross-national WMH publications can be found at http://www.hcp.med.harvard.edu/wmh/. In Belgium specifically, these activities were supported by the Belgian Fund for Scientific Research 1114717N/1114719N (GK, RB, PH), the King Baudouin Foundation 2014-J2140150-102905 (KDM, RB) and Eli Lilly IIT-H6U-BX-I002 (KDM, RB). In Australia, the project is funded by Suicide Prevention Australia. Philippe Mortier has a Sara Borrell contract awarded by the ISCIII (CD18/00049), and received funding from the Generalitat de Catalunya (2017 SGR 452) and the Belgian Fund for Scientific Research (11N0514N/11N0516N). Mark Boyes is supported by the National Health and Medical Research Council, Australia (Investigator Grant 1173043). We wish to thank the staff of the Student Health Centre and the Administration offices of KU Leuven and Curtin University for their support in the data collection.

\section{ROLE OF THE SPONSOR}

The funding sources had no role in the design and conduct of the study; collection, management, analysis, and interpretation of the data; preparation, review, and/or approval of the manuscript; and decision to submit the manuscript for publication.

\section{CONFLICT OF INTEREST}

In the past 3 years, Dr. Kessler received support for his epidemiological studies from Sanofi Aventis, he was a consultant for Johnson \& Johnson Wellness and Prevention, and served on an advisory board for the Johnson \& Johnson Services Inc. Lake Nona Life Project. Dr. Kessler is a co-owner of DataStat, Inc., a market research firm that carries out healthcare research. The other authors report no biomedical financial interests or potential conflicts of interest. 


\begin{abstract}
Objective: The Interpersonal Theory of Suicide (IPTS) posits fearlessness of death and pain tolerance as two components of suicide capability. The German Capability for Suicide Questionnaire (GCSQ) is the first measure of both these components, but few data are available on its psychometrics. We (1) examined the psychometric properties of the GCSQ, and used it to test (2) the latent structure of suicide capability and (3) its associations with suicidal behavior. Method: As part of the WHO World Mental Health International College Student Initiative, Belgian $(N=3715)$ and Australian $(N=2828)$ students completed the GCSQ (Dutch or English versions). Results: The factor structure of the GCSQ was well represented by two first-order factors (fearlessness of death, pain tolerance) and a higher-order suicide capability factor. The fearlessness of death scale and pain tolerance scale (minus two reversescored items) showed good reliability ( $\alpha=.81-.90)$. Fearlessness of death was associated with suicidal behaviors, but the pain tolerance scale was inversely associated with suicidal behaviors. Conclusions: Consistent with the Interpersonal Theory of Suicide, fearlessness of death and pain tolerance are components of a higher-order suicide capability construct. The GCSQ is a reliable measure of this construct, though its pain tolerance scale requires modification.
\end{abstract}

Keywords: Suicide capability; Interpersonal Theory of Suicide; Measurement; German Capability for Suicide Questionnaire; Factor analysis. 


\section{Introduction}

Suicide is one of the leading causes of death worldwide. Close to one million people die by suicide each year, with many more experiencing suicidal ideation or non-lethal suicide attempts (World Health Organisation, 2014). Suicidal thoughts and behavior appear to be particularly prevalent among college students, with $19.5-25.3 \%$ reporting lifetime suicidal ideation, 4.8-7.7\% having made a suicide plan, and 2.2-4.5\% a prior suicide attempt (Mortier et al., 2018a, 2018b). Given that the majority of people who think about suicide do not act on their thoughts, it is important to identify factors that might increase or decrease the risk of acting on suicidal thoughts. Joiner's Interpersonal Theory of Suicide (2005; Van Orden et al., 2010) is one of the leading theoretical accounts of suicidal behavior, proposing that for someone to make a suicide attempt they must meet two preconditions: they must have both the desire to die (i.e., suicide desire) and the capability to carry out the suicide attempt (i.e., suicide capability). The capability to attempt suicide is facilitated by both a fearlessness of death and pain tolerance. To assess these two components of suicide capability, Wachtel et al. (2014) introduced an 11-item self-report measure called the German Capability for Suicide Questionnaire (GCSQ). The current paper has three major objectives: (1) to evaluate the psychometric properties of the Dutch and English versions of GCSQ, and to use this measure to test (2) the latent structure of the suicide capability construct and (3) its associations with suicidal behavior.

Accurate assessment of the constructs that explain who is at risk of transitioning from suicide ideation to a suicide attempt will be able to provide both researchers and clinicians with a clinical tool to better assess and monitor suicide risk. Hence, it is important to validate the conceptual structure of such constructs and identify robust measures to assess them. Several measures have been developed to assess suicide capability (see George et al., 2016; Joiner et al., 2009; Ribeiro et al., 2014; Rimkeviciene et al., 2017), but the GCSQ was the 
first designed to assess both fearlessness of death and pain tolerance and may therefore have strong utility. For example, of the other available measures, Joiner et al.'s (2009) 20-item Acquired Capability for Suicide Scale (ACSS) has been perhaps the most widely used, but it has only one pain tolerance item so cannot provide a separate pain tolerance scale score. Similarly, Ribeiro et al.'s (2014) 7-item adaption of the ACSS (called the ACSS-FAD) assesses only one component, fearlessness of death. However, it is conceptually useful for a measure of suicide capability to assess both fearlessness of death and pain tolerance, as the Interpersonal Theory of Suicide specifies both as interacting or intercorrelated facets of a multidimensional suicide capability construct (Joiner, 2005). This theorised structure can be tested directly using higher-order factor analysis (i.e., by testing a higher-order factor model where first-order fearlessness of death and pain tolerance factors are specified to load together on a common higher-order suicide capability factor), however, such a factor model has not yet been tested using any suicide capability measure. The psychometric properties of the GCSQ have rarely been tested, and studies have only used the German language form (e.g., Wachtel et al., 2014). To enable more widespread assessments of suicide capability, validations of non-German language versions are required. Wachtel et al. (2014) provided an English version of the GCSQ as an appendix, but did not test its psychometric performance.

In the only existing factor analytic study of the GCSQ, Wachtel et al. (2014) tested and confirmed a two-factor structure (comprised of correlated fearlessness of death and pain tolerance factors); an additional item designed to assess perceived capability for suicide (" $I$ could kill myself if I wanted to [reverse-scored]") did not load on either factor but was retained because it related uniquely with lifetime suicide attempts (Wachtel et al., 2014). This two-factor model had adequate fit, though the two reverse-scored items in the pain tolerance scale did have lower factor loadings (loadings =.39-.42). It is possible that this was due to a reverse-scored item method factor not being specified in the factor model, as reverse-scored 
items can often disrupt the factor structure of self-report questionnaires (for a review, see van Sonderen et al., 2013). Across several studies, the two scale scores have demonstrated good internal consistency (Spangenberg et al., 2019; Teismann et al., 2016; Paahaus et al., 2019; Wachtel et al., 2015) and strong correlations with similar self-report measures (Wachtel et al., 2014). However, only the perceived capability item and the fearlessness of death scale reliably associate with suicidal behaviors, raising concerns about criterion validity of the pain tolerance scale (Paashaus et al., 2019; Spangenberg et al., 2019; Teismann et al., 2016; Wachtel et al., 2014). Given the relative lack of research on the psychometric properties of the GCSQ, there is a need for more work to determine its utility to both researchers and clinicans.

In this study, our first aim is to examine the psychometric properties (factor structure, factorial invariance, internal consistency, criterion validity) of the Dutch and English versions of the GCSQ. The Dutch version of the GCSQ that we used here was translated and backtranslated from the English version by bilingual members of our team. Our second aim is to use the GCSQ to test the latent structure of the suicide capability construct. We were particularly interested in modelling whether the fearlessness of death and pain tolerance factors could load together on a common higher-order factor, thus testing this key specification of the Interpersonal Theory of Suicide. Relatedly, for our third aim we also examined the prediction that these components of suicide capability might associate with suicidal behavior (i.e., that students who have attempted suicide will have higher GCSQ scores than those who experienced ideation or made a plan to attempt suicide but did not act on these thoughts).

\section{Method}

\section{Participants and Procedure}

Our two samples were first-year university students from MASKED UNIVERSITY in 
Belgium $(n=3715$; Response Rate $=41.4 \%)$ and MASKED UNIVERSITY in Australia $(n=2828:$ Response Rate $=11.8 \%)$. Ethical approval was granted by the respective university human research ethics committees, and all students provided informed consent. Data from both samples were collected as part of the WHO World Mental Health International College Student Initiative (WMH-ICS). The data presented in this study come from the 2016 and 2017 student cohorts at MASKED BELGIAN UNIVERSITY and the 2016, 2017, 2018, and 2019 cohorts at MASKED AUSTRALIAN UNIVERSITY. All students from these cohorts were invited to participate in the project at the beginning of the semester, which involved participants completing the standardized WMH-ICS online survey about their mental health. The Belgian and Australian sites included the GCSQ as an additional module in the survey; Belgian students completed the Dutch version and Australian students completed the English version. ${ }^{1}$ Demographic information for these samples and their respective sampling frame is provided in Table 1. Compared to the entire student cohorts (Belgium $N=8973$, Australia $N$ =23885), demographic proportions of the Belgian and Australian samples were largely similar, though respondents were more likely to be female than non-respondents. In the Australian sample, respondents were also likely to be younger, and more likely to have parents in the high education category compared to non-respondents (see Table 1).

---Table 1---

\section{Measures}

Two scale scores are designed to be derived from the German Capability for Suicide Questionnaire (Wachtel et al., 2014), corresponding to fearlessness of death (five items; e.g., "I am very much afraid to die") and pain tolerance (five items; e.g., "I can hardly stand pain"). Additionally, the GCSQ includes a single item indicator of perceived capability for

\footnotetext{
${ }^{1}$ Some participants in the Belgian $(n=38)$ and Australian $(n=18)$ samples had a small amount of missing data on the GCSQ (1 or 2 items missing). In these cases, missing data were replaced using the expectation-maximization method (Gold \& Bentler, 2000).
} 
suicide ("I could kill myself if I wanted to [reverse-scored]"). All items are answered on a 5point Likert scale, ranging from 1 (I fully agree) to 5 (I do not agree at all), with higher scores indicating a higher level of suicide capability. Three items (the perceived capability item and two items from the pain tolerance scale) are reverse-scored prior to calculating scale scores.

The lifetime occurrence of suicidal thoughts and behaviors was assessed via items from modified versions of the Self-Injurous Thoughts and Behaviors Interview (Nock et al., 2007) and Columbia Suicidal Severity Rating Scale (Posner et al., 2011). Specifically, three questions ask about participants' suicide ideation ("Did you ever in your life have thoughts of killing yourself?"), suicide plan ("Did you ever think about how you might kill yourself [e.g., taking pills, shooting yourself] or work out a plan of how to kill yourself?"), and suicide attempts ("Have you ever made a suicide attempt [i.e., purposefully hurt yourself with at least some intent to die]?). Each question was answered using a dichotomous (yes/no) answer format.

\section{Analytic strategy}

Confirmatory factor analyses (CFAs) were conducted using AMOS 25. All other analyses used SPSS 25. We examined the factor structure of the GCSQ using a series of CFAs (maximum likelihood estimation based on a Pearson covariance matrix). Prior to establishing measurement invariance, we ran these CFAs separately for the Belgian and Australian samples to establish the best factor structure in each sample.

We tested the following theoretically informed models (see Figure 1). A 1-factor model+perceived capability, which included all 11 GCSQ items specified to load on a single "general capability" factor. A 2-factor model+perceived capability, where the five fearlessness of death and five pain tolerance items were specified to load on separate "fearlessness of death" or "pain tolerance" factors, and the perceived capability item was allowed to load on both these factors (we anticipated, based on previous findings, that the 
perceived capability item would not load on either factor, but tested this here in the interest of completeness). A 2-factor model, as tested by Wachtel et al. (2014), where the five fearlessness of death and five pain tolerance items were specified to load on separate "fearlessness of death" or "pain tolerance" factors (and the perceived capability item was not included in the model). We also tested some variants of this 2-factor model, each representing a different way of testing the potential impact of the reverse-scored format of some of these items (Van Sonderen et al., 2013). These were a 2-factor model+method, which included a "method factor" comprised of the two reverse-scored items from the pain tolerance subscale; and a 2-factor model+items removed, where all reverse-scored items were removed from the model. Finally, we also tested higher-order variants of these above models, to determine whether the two first-order "fearlessness of death" and "pain tolerance" factors could load on a higher-order "general capability" factor. These included the higher-order model, which was a higher-order version of the 2-factor model; a higher-order model+method, which was a higher-order version of the 2-factor model+method; and a higher-order model+items removed, which was a higher-order version of the 2-factor model+items removed.

The goodness-of-fit of each model was judged based on the pattern of factor loadings and factor intercorrelations, and four fit indices: CFI, TLI, RMSEA, and SRMR. CFI and TLI values $\geq .90$ indicate acceptable fit, and $\geq .95$ excellent fit. RMSEA and SRMR values $\leq .08$ indicate acceptable fit, and $\leq .06$ excellent fit (Marsh et al., 2004; Byrne, 2016). We also used AIC to directly compare models (lower AIC values indicate better fit). Factor loadings $\geq .40$ were judged as meaningful loadings (Stevens, 2002).

---Figure 1---

We tested the invariance of the factor structure of the GCSQ across our Belgian and Australian samples using Byrne's (2016) procedure. A baseline configural model was tested with no equality constraints imposed, then a measurement model was tested with all factor 
loadings constrained to be equal across the samples, then a structural model was tested with all factor loadings and factor covariances constrained to be equal. A difference in CFI values of $<.01$ between the configural, measurement, and structural models indicates invariance (Cheung \& Rensvold, 2002).

Cronbach's alpha coefficients were calculated for each sample, with values $\geq .70$ considered acceptable (Groth-Marnat, 2009). The criterion validity of GCSQ scores was evaluated by testing associations with suicidal thoughts and behaviors. This was done for each national sample separately using Multivariate Analyses of Covariance (MANCOVAs). For these analyses, we divided our samples into four meaningful groups: respondents with no lifetime suicidal thoughts and behaviors, respondents reporting lifetime suicide ideation (but no plan or attempt), respondents reporting lifetime suicide ideation who also made a suicide plan, and respondents who made a suicide attempt at least once. These groups were used as the independent variable in our MANCOVAs, and GCSQ scores were the dependent variables. In line with the IPTS, students who made a suicide attempt should report higher scores than those who report suicide ideation or made a plan but did not act on these thoughts and plans. Because demographic factors can account for some variance in suicidal thoughts and behaviors among students (e.g., Lewinsohn et al., 2001; Mortier et al., 2017a; Mortier et al., 2017b; Mortier et al., 2018b; Taylor et al., 2005), participant demographic variables (age, gender, parental education, parental income) were entered as covariates.

\section{Results}

\section{Factor structure}

We found a similar pattern of CFA across the Belgian and Australian samples. Goodness-of-fit indices and factor loadings are provided in Tables 2 and 3, respectively. The 1-factor model+perceived capability was a poor fit in both samples $(\mathrm{CFI}=.703$, TLI $=.629$, RMSEA $=.178$, SRMR $=.142$ [Belgian sample]; CFI $=.693, \mathrm{TLI}=.616, \mathrm{RMSEA}=.181$, 
SRMR = .1364 [Australian sample]), highlighting that the GCSQ was assessing a multidimensional construct. The 2-factor model + perceived capability $(\mathrm{CFI}=.938, \mathrm{TLI}=$ .919$, RMSEA $=.083$, SRMR $=.058$ [Belgian sample $]$ CFI $=.877$, TLI $=.839$, RMSEA $=$ $.117, \mathrm{SRMR}=.090$ [Australian sample]) fit substantially better than the 1-factor model+perceived capability, indicating that there was value in distinguishing between the fearlessness of death and pain tolerance factors (estimated $r=.26$ [Belgian sample], .39 [Australian sample], $p \mathrm{~s}<.001)$. As anticipated, the perceived capability item did not load well on either of these factors in either sample (loadings $=-.05$ to .12 ), so this item was not included in our subsequent CFA models testing the fearlessness of death and pain tolerance dimensions. The 2-factor model (which did not include the perceived capability item) had acceptable fit indices in the Belgian sample $(\mathrm{CFI}=.953, \mathrm{TLI}=.938, \mathrm{RMSEA}=.079, \mathrm{SRMR}$ $=.053$ ), though in the Australian sample TLI, RMSEA, and SRMR values were outside the acceptable ranges $(\mathrm{CFI}=.902, \mathrm{TLI}=.870, \mathrm{RMSEA}=.115, \mathrm{SRMR}=.084) . \mathrm{In}$ both samples, the two reverse-scored items within the pain tolerance scale (items 7 and 11) had poor factor loadings on the pain tolerance factor. All other items loaded well on their intended factor (see Table 3). The addition of the reverse-scored item method factor into this model (2-factor model + method $)$ substantially improved levels of fit in both samples $(\mathrm{CFI}=.972, \mathrm{TLI}=.962$, RMSEA $=.063$, SRMR $=.039$ [Belgian sample $]$ CFI $=.954, \mathrm{TLI}=.937, \mathrm{RMSEA}=.080$, SRMR $=.058$ [Australian sample]), and items 7 and 11 loaded more highly on this method factor (loadings $=.48$ to .69 ) than on their intended pain tolerance factor (loadings $=.00$ to .30). There was therefore good evidence for a method effect in the GCSQ in both samples, and statistically, these two reverse-scored items were not good indicators of the latent pain tolerance construct. The removal of these two items improved model fit further, and the 2factor model+items removed was the best fitting model in both samples (alongside the higher-order version of this model), with most fit indices in the excellent range (CFI $=.984$, 
$\mathrm{TLI}=.977, \mathrm{RMSEA}=.060, \mathrm{SRMR}=.029[$ Belgian sample $]$ CFI $=.981, \mathrm{TLI}=.972$, RMSEA $=.065$, SRMR $=.303$ [Australian sample]). The two factors in this model were positively correlated (estimated $r=.27$ [Belgian sample], .40 [Australian sample], $p$ s $<.001$ ). In both samples, the higher-order models also fit well (see Table 2). For example, in the best fitting higher-order model (higher-order model+items removed), these two first-order factors both loaded strongly on the higher-order factor (loadings $=.48$ to .67 ) and all fit index values were in the excellent or acceptable range $(\mathrm{CFI}=.984, \mathrm{TLI}=.977, \mathrm{RMSEA}=.060, \mathrm{SRMR}=$ .029 [Belgian sample]; CFI $=.981, \mathrm{TLI}=.972, \mathrm{RMSEA}=.065, \mathrm{SRMR}=.303$ [Australian sample]). These findings therefore provide statistical evidence for fearlessness of death and pain tolerance being two components of a coherent, multidimensional suicide capability construct.

---Table 2---

---Table 3---

Factorial invariance. Based on our above CFA results, we tested the invariance of two of the best performing models: the 2-factor model+method and the higher-order model+items removed. The 2-factor model+method was selected for invariance testing because it allowed us to examine the invariance of the method factor and the correlation between the fearlessness of death and pain tolerance factors, and the higher-order model+items removed was selected because it was the best fitting model and this allowed us to examine the invariance of the higher-order factor structure. Both these factor structures were invariant across the Belgian and Australian samples; CFI values did not differ substantially between the configural, measurement, and structural models (see Table 4). ---Table 4---

\section{Descriptive Statistics and Internal Consistency}

GCSQ scores and Cronbach's alpha coefficients are displayed in Table 5. In both 
samples, reliability coefficients for the fearlessness of death scale were excellent. However, reliability coefficients for the pain tolerance scale were lower and just above the acceptable .70 threshold in the Belgian sample and in the poor range for the Australian sample $(\alpha=.65)$. The reliability of the pain tolerance scale appeared to be reduced by its two reverse-scored items. With items 7 and 11 removed, the reliability of this 3-item short pain tolerance scale improved markedly and was good in the Belgian sample and Australian samples $(\alpha=.81)$.

\section{---Table 5---}

\section{Criterion Validity}

In the Belgian sample, the percentage of participants that answered the suicide ideation, plan, and attempt questions was $93.4 \%, 93.0 \%$, and $98.4 \%$, respectively ${ }^{2}$. Of these, 2891 had no lifetime suicidal thoughts or behaviors, 280 reported only suicidal ideation, 242 reported suicide ideation and also made a suicide plan, and 59 reported a suicide attempt. In the Australian sample, the percentage of participants that answered the suicide ideation, plan, and attempt questions was $96.1 \%, 95.4 \%$, and $97.7 \%$, respectively. Of these, 1484 had no lifetime suicidal thoughts or behaviors, 374 reported suicidal ideation, 601 reported suicide ideation and also made a suicide plan, and 253 reported a suicide attempt.

Because our factor analyses suggested that GCSQ pain tolerance items 7 and 11 were poor indicators of their intended latent factor and were disruptive to this scale's internal consistency, we used the shorter 3-item version of the pain tolerance scale in our MANCOVAs. A similar pattern of findings emerged in both samples. The multivariate analysis indicated a significant main effect of group on the statistical composite of the three GCSQ scores (Belgian sample, $F(9,10392)=43.707, p<.001$, partial $\eta^{2}=.036$; Australian sample, $F(9,8019)=68.293, p<.001$, partial $\left.\eta^{2}=.071\right)$. Examination of univariate results

\footnotetext{
${ }^{2}$ Participants had the option "I don't want to answer".
} 
highlighted that, in both samples, all three dependent variables differed significantly between the groups (Belgian sample, $p$ s < .001-.027; Australian sample, $p$ s < .001).

Pairwise comparisons and estimated marginal means were inspected to determine which of the four groups were significantly different (see Table 6 and Tables S1 and S2 in the supplementary materials). In both samples, significant differences between the groups were noted in perceived capability, with increases from people with no history of suicidal thoughts and behavior, to those reporting ideation, plan, or attempt $(, p s<.001)$. A similar pattern was observed for fearlessness of death, whereby in both samples, participants reporting a suicide attempt reported the highest levels of fearlessness of death. Results for the GCSQ pain tolerance scale, however, indicated poorer criterion validity. In both samples, people with no history of suicidal thoughts or behavior reported the highest levels of pain tolerance. In the Belgian sample, these participants had significantly higher pain tolerance scores than all the other groups ( $p$ s <.001-.044). Participants who had attempted suicide did not differ significantly from participants reporting ideation alone $(p=.998)$ or those reporting both suicide ideation and a plan $(p=.731)$. Similarly, in the Australian sample, participants with no history of suicidal thoughts or behavour had significantly higher pain tolerance scores than all the other groups $(p s<.001)$, and scores for those who had made an attempt did not differ significantly from those reporting ideation only $(p=.901)$ or both ideation and plan $(p=$ $.633) .3$

\footnotetext{
${ }^{3}$ If the 5-item form of the pain tolerance scale is used in these analyses (instead of the 3-item form), the results differ slightly. In both samples, the results for the overall MANCOVA remain significant. However, in the Australian sample, the overall ANCOVA no longer indicates a significant difference between the groups for pain tolerance. For the Belgian sample, the ANCOVA is significant for pain tolerance $(p<.041)$, but pairwise comparisons indicate no significant differences between the groups ( $p \mathrm{~s}=.051-.256)$.

${ }^{4}$ If demographics are not controlled for as covariates in the analysis, the overall pattern of results remains similar, though there are some minor changes. Specifically, in the Belgian sample, the follow-up ANOVA for the fearlessness of death score shifts from significant to non-significant $(p=.066)$. This might be because gender was a significant covariate in the ANCOVA, though it could also be due to random error (see Spector \& Brannick, 2011).
} 


\section{Discussion}

Our aims were to examine the psychometric properties of the Dutch and English versions of the GCSQ, and use it to test the latent structure of the suicide capability construct and its associations with suicidal behaviors. In doing so, we hoped to determine the utility of this measure and test some key specifications of the Interpersonal Theory of Suicide. Overall, our results suggest that the Dutch and English versions of the GCSQ function similarly, and for the most part have good validity and reliability as markers of a coherent, multidimensional suicide capability construct.

In both samples, the factor structure of the GCSQ was well represented by two firstorder factors, corresponding to the two intended fearlessness of death and pain tolerance scales. There was, however, also evidence for a method effect (i.e., a reverse-scored item method factor), and the two reverse-scored items within the pain tolerance scale were poor indicators of their intended latent factor. Our results in this respect are therefore broadly consistent with Wachtel et al.'s (2014) previous factor analytic findings, where they found good support for the fearlessness of death and pain tolerance factors, but the two reversescored items from the pain tolerance scale functioned more poorly than the other items.

These method factor issues were also reflected in the internal consistency of the scales; the fearlessness of death scale had excellent reliability, but the full pain tolerance scale did not. Previous work with the GCSQ in German samples has usually found adequate reliability coefficients for the pain tolerance scale with all five items (e.g., Wachtel et al., 2014; Wachtel et al., 2015), but this was not the case for our Australian sample, and reliability in the Beligan sample was also impacted by the reverse-scored items. These findings are consistent with a growing body of literature in the psychological assessment field, which highlights that reverse-scored items often adversely affect the psychometric performance of self-report measures (van Sonderen et al., 2013). Because removing items 7 
and 11 from the pain tolerance scale score improved internal consistency, it might be beneficial to remove these items in future administrations of the GCSQ. ${ }^{5}$

Another key contribution of our study was the demonstration that a higher-order factor model fit well. A core feature of the Interpersonal Theory of Suicide is the specification that fearlessness of death and pain tolerance are two components of a coherent and multidimensional suicide capability construct (Van Orden et al., 2010). To the best of our knowledge, our study is the first to have directly tested this hypothesis using a higher-order factor analysis. The current findings are therefore of theoretical value, providing support for this key element of Joiner's (2005) theory.

The perceived capability item and fearlessness of death scale scores also appeared to have good utility in differentiating groups with suicidal thoughts and plans that did (or did not) also report a suicide attempt . The results for the pain tolerance scale were, however, less in line with our expectations. Pain tolerance scores were not elevated among participants who reported an attempt, but instead tended to be highest among participants with no history of suicidal thoughts or behavours. In this respect, our findings were somewhat similar to Wachtel et al.'s (2014) original development study, which also found support for the criterion validity of the perceived capability item and the fearlessness of death scale, but not the pain tolerance scale (see also, Paashaus et al., 2019; Teismann et al., 2016). Some of our findings also share similarities with those of Spangenberg et al. (2019), who observed lower (not higher) pain tolerance among participants with a history of suicide attempts. One explanation for these unexpected findings might be that, rather than simply being linked to the frequency or occurrence of suicide attempts, pain tolerance may be associated with an increased violence or lethality of the suicide attempt method (see Van Orden et al., 2010). We

\footnotetext{
${ }^{5}$ Item 6 (the perceived capability item) is technically also a reverse-scored item, though, it is presently unclear whether this formatting style has any adverse impact on its performance. In terms of associations with suicidal thoughts or behaviors it appears to be the strongest aspect of the GCSQ, so in our view it should be retained.
} 
unfortunately did not have data on this aspect of suicidal behavior, so we could not test this hypothesis. It is also possible that a suicide attempt may make some people aware that they cannot tolerate pain, or that some people with the most pain tolerance are not in our samples as they may have died by suicide. Alternatively, it might be that the pain tolerance items of the GCSQ require some improvements to better capture their intended construct. Presently, all items ask about pain generally rather than specifying physical pain; some participants might misinterpret these items as meaning tolerance of emotional pain, or some composite of both mental distress and physical pain. ${ }^{6}$ That said, similar patterns to what we observed here have been found when using other suicide capability measures (e.g., George et al., 2016). Prospective research that utilizes the GCSQ as part of a multi-method assessment of pain tolerance (e.g., with other self-report measures and objective markers) would be beneficial in further teasing out the potential links between pain tolerance and suicidal thoughts and behaviors. Of note, the theory would propose that pain tolerance and fearlessness of death interact with ideation to predict future suicide attempts, such that the relationship between ideation and attempts should be stronger when both pain tolerance and fearlessness of death are high.

Taken together, our data therefore suggest those working with individuals at risk of suicide might, in particular, look out for elevated scores on the fearlessness of death scale and perceived capability item. Given the strong performance of the perceived capability item in this and previous studies (e.g., Wachtel et al., 2014), the inclusion of this variable in the GCSQ beyond just the fearlessness of death and pain tolerance scale scores may represent a useful advantage for the GCSQ over other suicide capability measures.

\footnotetext{
${ }^{6}$ Prior studies have suggested that people at risk for suicide have a lower tolerance for emotional pain, leading to desire to escape and suicidal thoughts (for a review, see Hooley et al., 2014).
} 


\section{Limitations and Future Directions}

While the current study makes a useful contribution, the following limitations should be noted that will require further research. First, we did not administer any other measures of suicide capability against which to compare the GCSQ. George et al. (2016) recently introduced the Acquired Capability with Rehearsal for Suicide Scale, which like the GCSQ includes both fearlessness of death and pain tolerance items. Direct comparisons between these measures in future studies could help to explore concurrent and discriminant validity. Second, we did not examine factorial invariance against the original German version of the GCSQ. Hence, whilst our data indicate that the Dutch and English versions of the GCSQ perform similarly, we cannot comment on whether this is also the case for the German form. Third, although rates of suicidal thoughts and behaviors are high among university students (Mortier et al., 2018a, 2018b), future work examining the GCSQ in general community and clinical samples would be beneficial to determine the generalisability of our findings to other populations. Fourth, because the GCSQ has only one perceived capability for suicide item, this limited our ability to represent perceived capability as a factor in our CFAs or test for mean group differences within a latent variable framework (multiple items/indicators are needed for a robust latent factor; e.g., Little et al., 1999). As perceived capability appears to be uniquely associated with suicidal behavior, it could be useful for future studies to develop additional perceived capability items to enable this construct to be modeled more robustly. Fifth, the Interpersonal Theory of Suicide hypothesizes that suicide desire (operationalized as thwarted belonginess and perceived burdensomenesss) interacts with suicide capability in leading to suicide attempts, but we did not measure these constructs. Future work could therefore be strengthened by the administration of suicide desire measures (e.g., Van Orden et al., 2012).

\section{Conclusions}


Our data suggest that the Dutch and English versions of the GCSQ function similarly, and have good levels of validity and reliability as markers of a coherent and multidimensional suicide capability construct. However, the pain tolerance scale may function better without the reverse-scored items. More prospective research is needed to establish the predictive utility of fearlessness of death and pain tolerance in predicting suicide risk. 


\section{References}

Byrne, B. M. (2016). Structural equation modeling with AMOS: Basic concepts, applications, and programming. Routledge.

Cheung, G. W., \& Rensvold, R. B. (2002). Evaluating goodness-of-fit indexes for testing measurement invariance. Structural Equation Modeling, 9, 233-255.

George, S. E., Page, A. C., Hooke, G. R., \& Stritzke, W. G. (2016). Multifacet assessment of capability for suicide: Development and prospective validation of the Acquired Capability With Rehearsal for Suicide Scale. Psychological Assessment, 28, 1452.

Gold, M. S., \& Bentler, P. M. (2000). Treatments of missing data: A Monte Carlo comparison of RBHDI, iterative stochastic regression imputation, and expectationmaximization. Structural Equation Modeling, 7, 319-355.

Groth-Marnat, G. (2009). Handbook of psychological assessment. John Wiley \& Sons.

Hooley, J. M., Franklin, J. C., \& Nock, M. K. (2014). Chronic pain and suicide: understanding the association. Current Pain and Headache Reports, 18, 435.

Joiner, T. (2005). Why people die by suicide. Harvard University Press.

Joiner, T. E., Van Orden, K. A., Witte, T. K., \& Rudd, M. D. (2009). The interpersonal theory of suicide: Guidance for working with suicidal clients. American Psychological Association.

Lewinsohn, P. M., Rohde, P., Seeley, J. R., \& Baldwin, C. L. (2001). Gender differences in suicide attempts from adolescence to young adulthood. Journal of the American Academy of Child and Adolescent Psychiatry, 40, 427-434. 
Little, T. D., Lindenberger, U., \& Nesselroade, J. R. (1999). On selecting indicators for multivariate measurement and modeling with latent variables: When "good" indicators are bad and "bad" indicators are good. Psychological Methods, 4, 192-211.

Marsh, H. W., Hau, K. T., \& Wen, Z. (2004). In search of golden rules: Comment on hypothesis-testing approaches to setting cutoff values for fit indexes and dangers in overgeneralizing Hu and Bentler's (1999) findings. Structural Equation Modeling, 11, $320-341$.

Mortier, P., Kiekens, G., Auerbach, R. P., Cuijpers, P., Demyttenaere, K., Green, J. G., ... \& Bruffaerts, R. (2017a). A risk algorithm for the persistence of suicidal thoughts and behaviors during college. The Journal of Clinical Psychiatry, 78, e828.

Mortier, P., Demyttenaere, K., Auerbach, R. P., Cuijpers, P., Green, J. G., Kiekens, G., ... \& Bruffaerts, R. (2017b). First onset of suicidal thoughts and behaviours in college. Journal of Affective Disorders, 207, 291-299.

Mortier, P., Auerbach, R. P., Alonso, J., Bantjes, J., Benjet, C., Cuijpers, P., ... \& O’Neill, S. (2018a). Suicidal thoughts and behaviors among first-year college students: Results from the WMH-ICS project. Journal of the American Academy of Child \& Adolescent Psychiatry, 57(4), 263-273.

Mortier, P., Cuijpers, P., Kiekens, G., Auerbach, R. P., Demyttenaere, K., Green, J. G., ... \& Bruffaerts, R. (2018b). The prevalence of suicidal thoughts and behaviours among college students: a meta-analysis. Psychological Medicine, 48, 554-565.

Nock, M. K., Holmberg, E. B., Photos, V. I., \& Michel, B. D. (2007). Self-Injurious Thoughts and Behaviors Interview: Development, reliability, and validity in an adolescent sample. Psychological Assessment, 19, 309-317. 
Paashaus, L., Forkmann, T., Glaesmer, H., Juckel, G., Rath, D., Schönfelder, A., ... \& Teismann, T. (2019). Do suicide attempters and suicide ideators differ in capability for suicide?. Psychiatry research, 275, 304-309.

Posner, K., Brown, G. K., Stanley, B., Brent, D. A., Yershova, K. V., Oquendo, M. A., ... \& Mann, J. J. (2011). The Columbia-Suicide Severity Rating Scale: initial validity and internal consistency findings from three multisite studies with adolescents and adults. American journal of psychiatry, 168, 1266-1277.

Ribeiro, J. D., Witte, T. K., Van Orden, K. A., Selby, E. A., Gordon, K. H., Bender, T. W., \& Joiner Jr, T. E. (2014). Fearlessness about death: The psychometric properties and construct validity of the revision to the Acquired Capability for Suicide Scale. Psychological Assessment, 26, 115.

Rimkeviciene, J., Hawgood, J., O’Gorman, J., \& De Leo, D. (2017). Construct validity of the acquired capability for suicide scale: Factor structure, convergent and discriminant validity. Journal of Psychopathology and Behavioral Assessment, 39, 291-302.

Smith, P. N., Wolford-Clevenger, C., Mandracchia, J. T., \& Jahn, D. R. (2013). An exploratory factor analysis of the Acquired Capability for Suicide Scale in male prison inmates. Psychological Services, 10, 97.

Spangenberg, L., Glaesmer, H., Hallensleben, N., Rath, D., \& Forkmann, T. (2019). (In) stability of Capability for Suicide in Psychiatric Inpatients: Longitudinal Assessment Using Ecological Momentary Assessments. Suicide and Life-Threatening Behavior, 1-13.

Spector, P. E., \& Brannick, M. T. (2011). Methodological urban legends: The misuse of statistical control variables. Organizational Research Methods, 14, 287-305. 
Stevens, J. P. (2002). Applied multivariate statistics for the social sciences. Hillsdale: Erlbaum.

Taylor, R., Page, A., Morrell, S., Harrison, J., \& Carter, G. (2005). Mental health and socioeconomic variations in Australian suicide. Social Science and Medicine, 61, 15511559.

Teismann, T., Pläp, L., Prinz, S., \& Cwik, J. C. (2017). Fearlessness about death and perceived capability to die by suicide in seventh, eighth and ninth graders. Suicidology Online, 8, 32-39.

Wachtel, S., Vocks, S., Edel, M. A., Nyhuis, P., Willutzki, U., \& Teismann, T. (2014). Validation and psychometric properties of the German Capability for Suicide Questionnaire. Comprehensive Psychiatry, 55, 1292-1302.

Wachtel, S., Siegmann, P., Ocklenburg, C., Hebermehl, L., Willutzki, U., \& Teismann, T. (2015). Acquired Capability for Suicide, Pain Tolerance, and Fearlessness of PainValidation of the Pain Tolerance Scale of the German Capability for Suicide Questionnaire. Suicide and Life-Threatening Behavior, 45, 541-555.

Van Orden, K. A., Witte, T. K., Cukrowicz, K. C., Braithwaite, S. R., Selby, E. A., \& Joiner, T. E. (2010). The interpersonal theory of suicide. Psychological Review, 117, 575.

Van Orden, K. A., Cukrowicz, K. C., Witte, T. K., \& Joiner, T. E. (2012). Thwarted belongingness and perceived burdensomeness: Construct validity and psychometric properties of the Interpersonal Needs Questionnaire. Psychological Assessment, 24, 197.

Van Sonderen, E., Sanderman, R., \& Coyne, J. C. (2013). Ineffectiveness of reverse wording of questionnaire items: Let's learn from cows in the rain. PloS one, 8(7), e68967. 
Table 1

Demographics for the Belgian and Australian Samples (Survey Repondents and the Whole Student Cohorts from which they were Drawn)

\begin{tabular}{|c|c|c|c|c|c|c|c|c|}
\hline & \multicolumn{2}{|c|}{$\begin{array}{c}\text { Belgian survey } \\
\text { respondents } \\
(N=3715)\end{array}$} & \multicolumn{2}{|c|}{$\begin{array}{c}\text { Belgian whole } \\
\text { student cohort } \\
(N=8973)\end{array}$} & \multicolumn{2}{|c|}{$\begin{array}{c}\text { Australian survey } \\
\text { respondents }(N=2828)\end{array}$} & \multicolumn{2}{|c|}{$\begin{array}{c}\text { Australian whole } \\
\text { student cohort } \\
(N=23885)\end{array}$} \\
\hline & Frequency & $\%$ & Frequency & $\%$ & Frequency & $\%$ & Frequency & $\%$ \\
\hline \multicolumn{9}{|l|}{ Age (years) } \\
\hline$\leq 17$ & 167 & 4.5 & 251 & $2.8^{*}$ & 133 & 4.8 & 1018 & 4.3 \\
\hline 18 & 2470 & 66.5 & 5984 & 66.7 & 1196 & 42.8 & 8919 & $37.3 *$ \\
\hline 19 & 882 & 23.7 & 2221 & 24.8 & 538 & 19.2 & 4912 & 20.6 \\
\hline$\geq 20$ & 196 & 5.3 & 517 & 5.8 & 930 & 33.3 & 9036 & $37.8 *$ \\
\hline \multicolumn{9}{|l|}{ Gender } \\
\hline Female & 2323 & 62.5 & 5146 & $57.3 *$ & 1896 & 67.8 & 13230 & $55.4^{*}$ \\
\hline Male & 1392 & 37.5 & 3827 & $42.7^{*}$ & 901 & 32.2 & 10655 & $44.6^{*}$ \\
\hline \multicolumn{9}{|l|}{$\begin{array}{l}\text { Parental } \\
\text { Education }\end{array}$} \\
\hline Both low & 551 & 14.8 & 1384 & 15.4 & 772 & 27.6 & 7496 & $31.4 *$ \\
\hline Mixed & 846 & 22.8 & 2032 & 22.6 & 695 & 24.9 & 6284 & 26.3 \\
\hline Both high & 2318 & 62.4 & 5557 & 61.9 & 1330 & 47.6 & 10105 & $42.3^{*}$ \\
\hline \multicolumn{9}{|l|}{$\begin{array}{l}\text { Parental } \\
\text { financial } \\
\text { situation }\end{array}$} \\
\hline $\begin{array}{l}\text { Very easy to fairly } \\
\text { easy }\end{array}$ & 3063 & 82.4 & 7424 & 82.7 & - & - & - & - \\
\hline $\begin{array}{l}\text { Fairly difficult to } \\
\text { very difficult }\end{array}$ & 652 & 17.6 & 1549 & 17.3 & - & - & - & - \\
\hline Low SES & - & - & - & - & 522 & 18.7 & 4676 & 19.6 \\
\hline Middle SES & - & - & - & - & 1489 & 53.2 & 12569 & 52.6 \\
\hline High SES & - & - & - & - & 786 & 28.1 & 6640 & 27.8 \\
\hline
\end{tabular}

Note. ${ }^{*}$ Chi-square test indicating that the proportion of participants in that demographic category for the responder sample differs ( $p<.05$, Bonferroni corrected) compared to the proportion in the whole student cohort. Demographic information was unavailable for 31 of the Australian respondents. The parent financial situation variable was categorised slightly differently for the Belgian and Australian samples: in the Belgian sample the categories were 'very easy to fairly easy' and 'fairly difficult to very difficult', whereas in the Australian sample the categories were 'low', 'middle', and 'high' SES. 
Table 2

Goodness-of-Fit Index Values for the Different Confirmatory Factor Analysis Models

\begin{tabular}{|c|c|c|c|c|c|c|}
\hline Model & $\chi^{2}(d f)$ & CFI & TLI & RMSEA (90\% CI) & SRMR & AIC \\
\hline \multicolumn{7}{|l|}{ Belgian sample } \\
\hline 1-factor model+perceived capability & $5204.464(44)$ & .703 & .629 & $.178(.174-.182)$ & .1417 & 5248.464 \\
\hline 2-factor model+perceived capability & $1112.427(42)$ & .938 & .919 & $.083(.079-.087)$ & .0578 & 1160.427 \\
\hline 2-factor model & $829.812(34)$ & .953 & .938 & $.079(.075-.084)$ & .0528 & 871.812 \\
\hline 2-factor model+method & $518.484(33)$ & .972 & .961 & $.063(.058-.068)$ & .0388 & 562.484 \\
\hline 2-factor model+items removed & $272.644(19)$ & .984 & .977 & $.060(.054-.066)$ & .0285 & 306.644 \\
\hline Higher-order model & $829.812(34)$ & .953 & .938 & $.079(.075-.084)$ & .0528 & 871.812 \\
\hline Higher-order model+method & $518.484(33)$ & .972 & .961 & $.063(.058-.068)$ & .0388 & 562.484 \\
\hline Higher-order model+items removed & $272.644(19)$ & .984 & .977 & $.060(.054-.066)$ & .0285 & 306.644 \\
\hline \multicolumn{7}{|l|}{ Australian sample } \\
\hline 1-factor model+perceived capability & $4137.293(44)$ & 693 & 616 & $.181(.177-.186)$ & .1364 & 4181.293 \\
\hline 2-factor model+percieved capability & $1679.856(42)$ & .877 & .839 & $.117(.113-.122)$ & .0903 & 1727.856 \\
\hline 2-factor model & $1302.768(34)$ & .902 & .870 & $.115(.110-.120)$ & .0844 & 1344.768 \\
\hline 2-factor model+method & $633.612(33)$ & .954 & .937 & $.080(.075-.086)$ & .0581 & 677.612 \\
\hline 2-factor model+items removed & $243.208(19)$ & .981 & .972 & $.065(.057-.072)$ & .303 & 277.208 \\
\hline Higher-order model & $1302.768(34)$ & .902 & .870 & $.115(.110-.120)$ & .0844 & 1344.768 \\
\hline Higher-order model+method & $633.612(33)$ & .954 & .937 & $.080(.075-.086)$ & .0581 & 677.612 \\
\hline Higher-order model+items removed & $243.208(19)$ & .981 & .972 & $.065(.057-.072)$ & .0303 & 277.208 \\
\hline
\end{tabular}


Table 3. Standardised Factor Loadings from Confirmatory Factor Analyses of the German Capability for Suicide Questionnaire

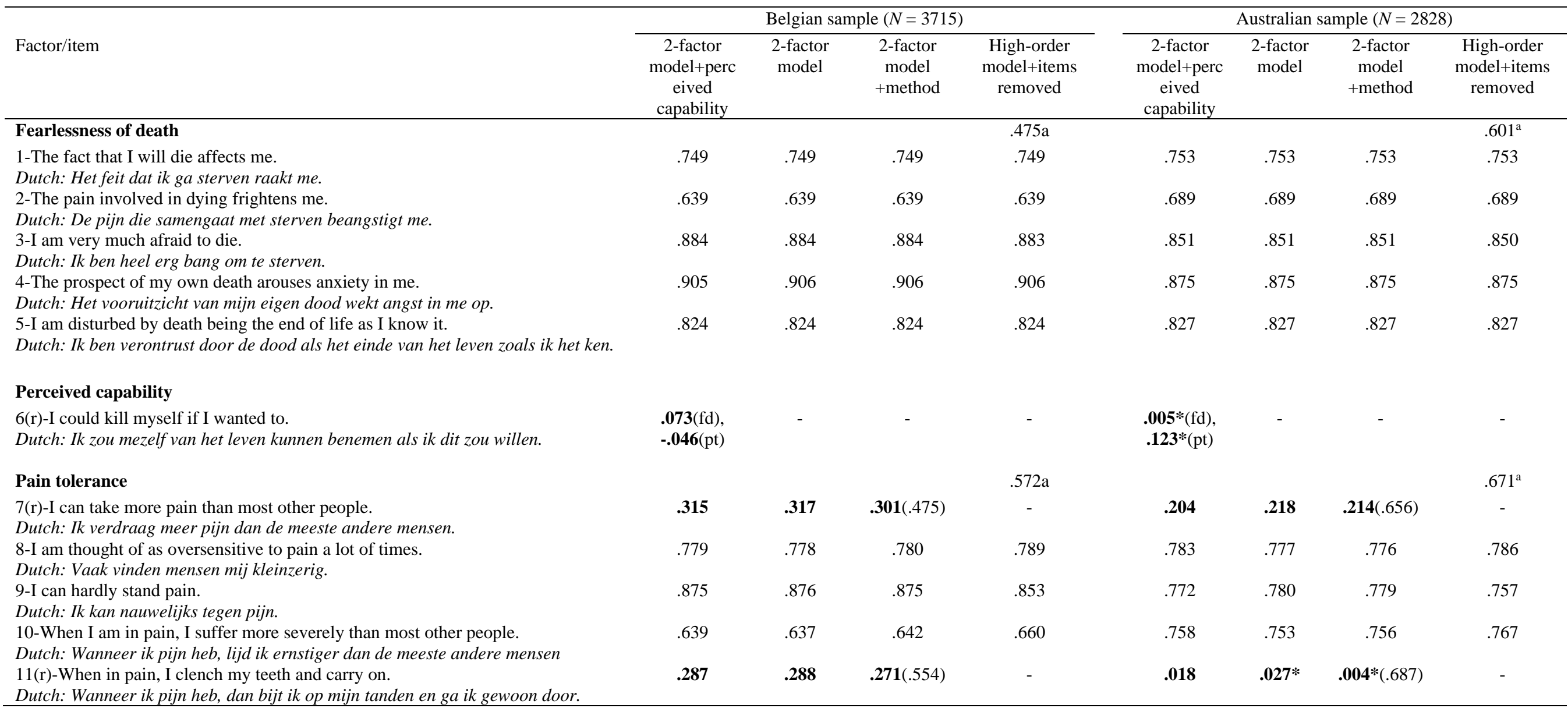

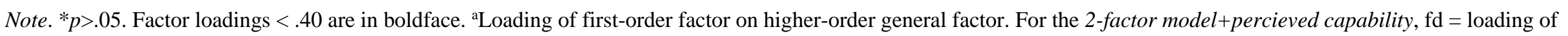
perceived capability item on fearlessness of death factor, $\mathrm{pt}=$ loading of perceived capability item on pain tolerance factor. Reverse-scored items are indicated with (r), and the factor loadings in brackets for the method factor models indicate the factor loadings of those items on the method factor. 
Table 4

Goodness-of-Fit Indices from Factorial Invariance Testing Across the Belgian and Australian Samples of the 2-Factor Model+Method and the Higher-Order Model+Items Removed

\begin{tabular}{lcccccc}
\hline Model & \multicolumn{1}{c}{$\boldsymbol{\chi}^{\mathbf{2}}(\boldsymbol{d} \boldsymbol{f})$} & CFI & TLI & RMSEA (90\% CI) & SRMR & AIC \\
\hline 2-factor model+method & & & & & & \\
Configural model & $1152.108(66)$ & .964 & .951 & $.050(.048-.053)$ & .0581 & 1240.108 \\
Measurement model & $1317.155(74)$ & .959 & .950 & $.051(.048-.053)$ & .0739 & 1389.155 \\
Structural model & $1355.727(75)$ & .957 & .949 & $.051(.049-.053)$ & .0786 & 1425.727 \\
& & & & & \\
Higher-order model+items removed & $515.854(38)$ & .983 & .975 & $.044(.041-.047)$ & .0303 & 583.854 \\
Configural model & $603.961(44)$ & .980 & .974 & $.044(.041-.047)$ & .0324 & 659.961 \\
Measurement model & $603.961(44)$ & .980 & .974 & $.044(.041-.047)$ & .0324 & 659.961 \\
Structural model & & & & & &
\end{tabular}

Note . CFI = Comparative Fit Index, TLI $=$ Tucker-Lewis Index, RMSEA $=$ Root Mean Square Error of Approximation, SRMR = Standardised Root Mean Square Residual, AIC = Akaike Information Criterion. 
Table 5

Descriptive Statistics and Cronbach's Alpha ( $\alpha$ ) Reliability Coefficients for the GSCQ in the Belgian and Australian Samples

\begin{tabular}{|c|c|c|c|c|c|c|c|c|}
\hline & \multicolumn{4}{|c|}{ Belgian sample $(N=3715)$} & \multicolumn{4}{|c|}{ Australian sample $(N=2828)$} \\
\hline & $M$ & $S D$ & range & $\alpha$ & $M$ & $S D$ & range & $\alpha$ \\
\hline Fearlessness of death & 15.75 & 5.48 & $5-25$ & .90 & 15.46 & 5.93 & $5-25$ & .90 \\
\hline Pain tolerance & 18.26 & 3.33 & $5-25$ & .71 & 17.68 & 3.79 & $5-25$ & .65 \\
\hline Pain tolerance (short) & 11.92 & 2.49 & $3-15$ & .81 & 11.37 & 2.93 & $3-15$ & .81 \\
\hline Perceived capability item & 1.82 & 1.14 & $1-5$ & - & 2.27 & 1.39 & $1-5$ & - \\
\hline
\end{tabular}

Note. Cronbach's alpha cannot be calculated for perceived capability because the score is comprised of a single item. The pain tolerance (short) scale is a 3-item version of the pain tolerance scale with items 7 and 11 removed. $M=$ mean, $S D=$ Standard deviation. 
Table 6

Estimated Marginal Means (and Standard Errors) from MANCOVA Analyses of GSCQ Scores across the Four Suicide-Related Thoughts and Behavior Groups in the Belgian and Australian Samples

\begin{tabular}{|c|c|c|c|c|c|c|c|c|}
\hline & \multicolumn{4}{|c|}{ Belgian sample } & \multicolumn{4}{|c|}{ Australian sample } \\
\hline & $\begin{array}{c}\text { No } \\
\text { suicidal } \\
\text { thoughts } \\
\text { or } \\
\text { behavior } \\
(n=2891)\end{array}$ & $\begin{array}{c}\text { Suicide } \\
\text { ideation } \\
\text { only } \\
(n=280)\end{array}$ & $\begin{array}{l}\text { Suicide } \\
\text { ideation } \\
\text { and plan } \\
(n=242)\end{array}$ & $\begin{array}{l}\text { Suicide } \\
\text { attempt } \\
(n=59)\end{array}$ & $\begin{array}{c}\text { No } \\
\text { suicidal } \\
\text { thoughts } \\
\text { or } \\
\text { behavior } \\
(n=1468)\end{array}$ & $\begin{array}{c}\text { Suicide } \\
\text { ideation } \\
\text { only } \\
(n=370)\end{array}$ & $\begin{array}{c}\text { Suicide } \\
\text { ideation } \\
\text { and plan } \\
(n=591)\end{array}$ & $\begin{array}{l}\text { Suicide } \\
\text { attempt } \\
(n=252)\end{array}$ \\
\hline Fearlessn & $15.81(.10$ & $15.14(.32$ & $16.06(.3$ & $17.30(.7$ & $15.84(.15$ & $14.17(.31$ & $15.27(.24$ & $16.34(.3$ \\
\hline $\begin{array}{l}\text { ess of } \\
\text { death }\end{array}$ & )$^{*}$ & )$^{*}$ & 5) & 1) & ) & )$^{*}$ & )$^{*}$ & 7) \\
\hline Pain & $12.07(.05$ & $11.42(.15$ & $11.29(.1$ & $11.42(.3$ & $11.80(.08$ & $10.82(.15$ & $10.96(.12$ & $10.85(.1$ \\
\hline $\begin{array}{l}\text { tolerance } \\
\text { (short) }\end{array}$ & )$^{*}$ & ) & 6) & 2) & )$^{*}$ & ) & ) & 8) \\
\hline $\begin{array}{l}\text { Perceived } \\
\text { capability }\end{array}$ & $\begin{array}{c}1.66(.02) \\
*\end{array}$ & $\begin{array}{c}2.14(.06) \\
*\end{array}$ & $\begin{array}{c}2.74(.07 \\
)^{*}\end{array}$ & $\begin{array}{c}3.35(.14 \\
)\end{array}$ & $\begin{array}{c}1.76(.03) \\
*\end{array}$ & $\begin{array}{c}2.30(.07) \\
*\end{array}$ & $\begin{array}{c}2.98(.05) \\
*\end{array}$ & $\begin{array}{c}3.41(.08 \\
)\end{array}$ \\
\hline
\end{tabular}

Note. $* p<.05$, in terms of being significantly different from the suicide attempt group in pairwise comparisons. Estimated marginal means are displayed outside of the brackets, and standard errors are displayed inside the brackets. All estimated marginal means are corrected for the following covariates: participant age, gender, parental education, and parental income. In terms of pain tolerance, a short 3-item version of the pain tolerance scale was used in these analyses due to its higher reliability. Results using the full 5-item pain tolerance scale are described in footnote 3. 
1-factor model + percieved capability

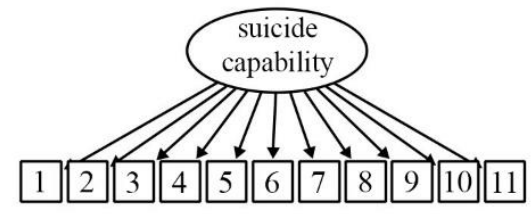

2-factor model+percieved capability

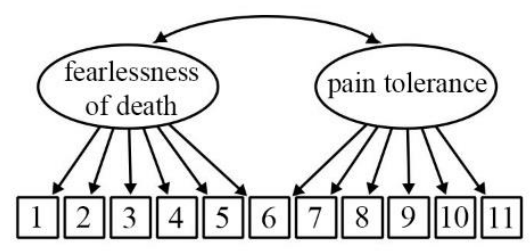

2-factor model

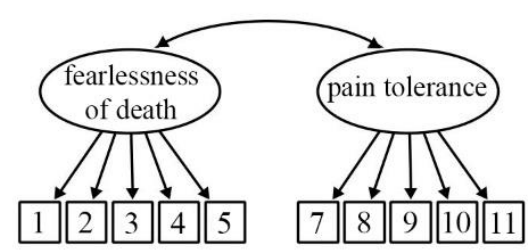

2-factor model + method

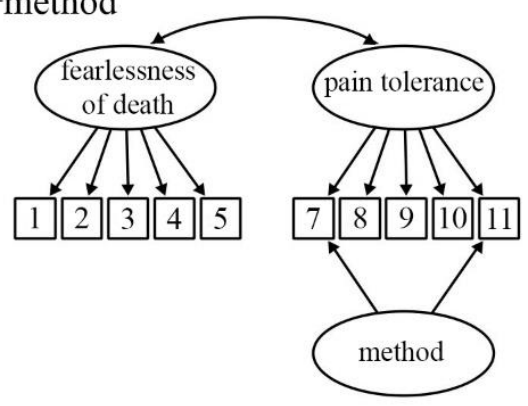

2-factor model+items removed

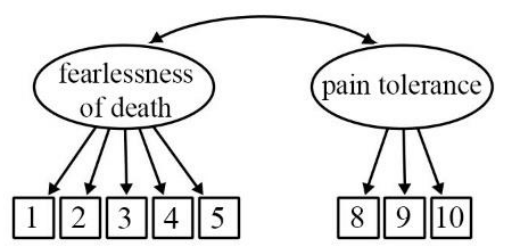

higher-order model

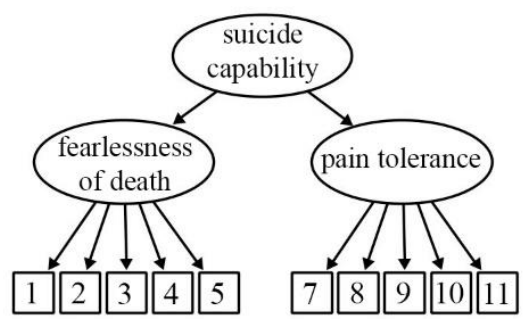

higher-order model+method

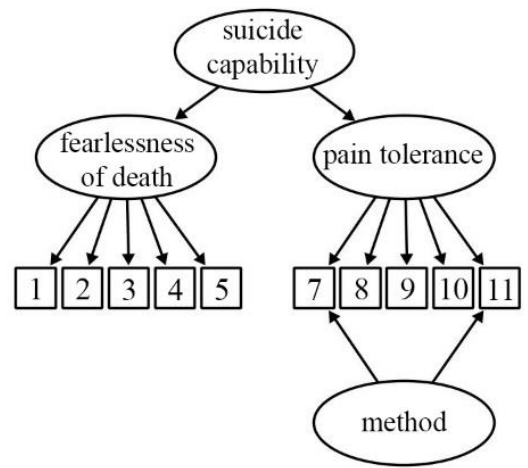

higher-order model+items removed

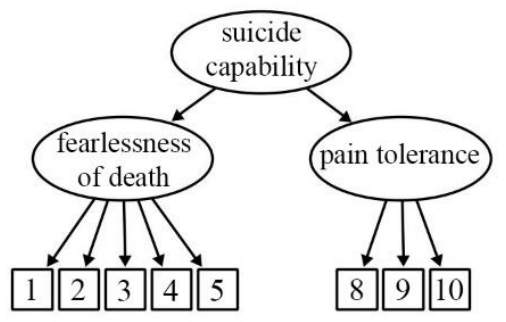

Figure 1. A visual representation of the different confirmatory factor analysis models assessed for the GCSQ. Squares represent item numbers and ellipses represent latent factors. Each item had an associated error term. 